\title{
HISTORIA
}

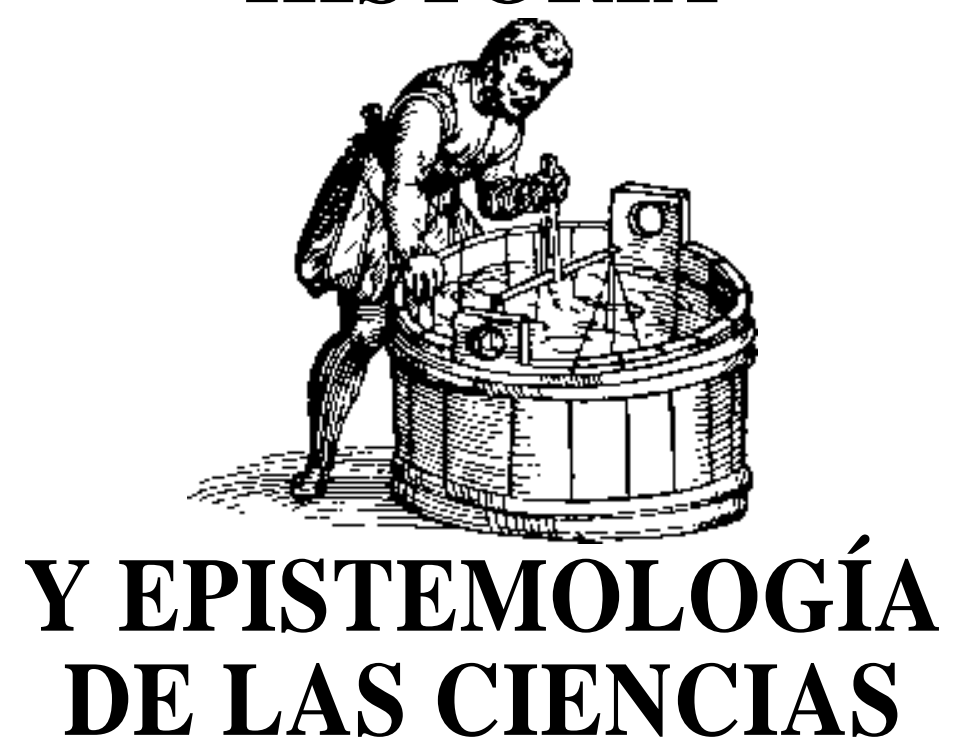

\section{DE LOS OBSTÁCULOS EPISTEMOLÓGICOS A LOS CONCEPTOS ESTRUCTURANTES: UNA APROXIMACIÓN A LA ENSEÑANZA- APRENDIZAJE DE LA GEOLOGÍA}

GARCÍA CRUZ, C.M.

IES Mencey Acaymo. Poeta Arístides Hernández Mora, s/n. 38500 Güímar. Tenerife.

Dirección electrónica: cmgct@correo.rcanaria.es

\begin{abstract}
SUMMARY
Starting from the Bachelard's model of knowledge construction based upon the notion of scientific change through epistemological obstacles, breaks and acts, Gagliardi's ideas about the structurant concepts, as a first approach to the learning-teaching of geology, are analysed. From a historical view, both deep-rooted ideas such as the natural theology derived from Genesis, and the improper use of right methodologies such as Actualism or the emphasis on direct observation, among others, have been constituted on their own as major epistemological obstacles. Likewise, the difficulty of direct observation and experimentation, the ideas of both the Earth as a whole and an accumulative science, the fixity, and the actualism, are pointed out as general obstacles affecting on the school learning of geology.
\end{abstract}




\section{INTRODUCCIÓN}

Las consideraciones hechas por la escuela francesa de filosofía de la ciencia, tanto en los aspectos epistemológicos como de comprensión del desarrollo histórico de la propia ciencia, han sido transcendentales. Dentro de esta escuela destacó principalmente Gaston Bachelard, que influyó decisivamente en filósofos e historiadores como Michel Foucault, Loáis Althusser o Michel Serres. Aunque las concepciones epistemológicas e históricas fundamentales de esta escuela poseen más de medio siglo, su repercusión didáctica está siendo ahora nuevamente valorada en los ámbitos educativos, en especial en educación secundaria.

Partiendo de los planteamientos epistemológicos de Gaston Bachelard, y en relación con los mismos, en este trabajo vamos a analizar las ideas de Gagliardi (1986) acerca de los conceptos estructurantes, así como la repercusión, y por lo tanto su importancia, de la historia de la ciencia en el proceso de enseñanza-aprendizaje de las ciencias de la Tierra, y en concreto de la geología.

\section{EL MODELO DE BACHELARD}

Las ideas básicas de Bachelard (1938) entapizan la importancia que tiene ofrecer una visión de la ciencia mediante los aspectos históricos que han influido en la construcción del conocimiento. Partiendo siempre de una catarsis intelectual, el modelo bachelardiano se basa en la idea de cambio científico, dentro del cual existen tres categorías bien definidas en el marco de la epistemología:

1) Obstáculos epistemológicos: Se trata de formas de pensar arraigadas, antiguas estructuras, tanto conceptuales como metodológicas, que pudieron tener en el pasado un cierto valor, pero que en un momento dado obstaculizan el progreso del conocimiento científico. Dichos obstáculos pueden reflejar fielmente la ideología dominante -o con pretensiones de serlo- en una época determinada y, por lo tanto, describir perfectamente la relación ciencia-técnica-sociedad.

Una de las principales fuentes de obstáculos epistemológicos es el sentido común. El mejor ejemplo de ello, lo podemos encontrar en el animismo primitivo, posteriormente traducido en el organicismo griego, que intentaba explicar el mundo por analogía con los procesos vitales. A través de estas analogías se llegó a establecer una relación, al igual que hace actualmente la geología, entre volcanes y terremotos, pero cuya explicación moderna obviamente nada tiene que ver con la circulación del fuego interior. Por otro lado, también se pueden convertir en fuente de obstáculos epistemológicos los mecanismos intuitivos que han hecho de metodologías y trabajos científicos correctos, verdaderos impedimentos para el avance de la ciencia. Los métodos de observación directa se convirtieron en un importante obstáculo epistemológico debido al énfasis puesto en ellos durante el siglo
XVII por parte del positivismo inductivista. Esto condujo al rechazo de la metodología hipotético-deductiva y, en consecuencia, se vio afectado tanto el desarrollo como la aceptación de algunas teorías como, por ejemplo, la deriva continental.

En los ejemplos anteriores vemos cómo el sentido común y la intuición pueden contribuir negativamente en el avance científico, así como la influencia de estos aspectos de la fillosofía aristotélica en el lento desarrollo de la ciencia durante muchos siglos. No se les debería dar, pues, más que el valor primario, muy elemental, que de hecho poseen.

2) Rupturas epistemológicas: En términos generales, son las formas en que el conocimiento científico contradice las ideas o creencias que proceden de un conocimiento ante todo primario, intuitivo y de sentido común. También se considera como ruptura epistemológica la que se produce entre dos concepciones científicas distintas, tanto para un conocimiento dado como para una metodología concreta. Toda ruptura implica la superación del correspondiente obstáculo.

En ocasiones, las rupturas sociales, como la reforma protestante o la revolución francesa, abonaron el camino para las rupturas científicas. Las más importantes rupturas epistemológicas se han producido generalmente por medio de grandes, y a veces largas, controversias. Éstas surgen en el ámbito de la ciencia bajo dos situaciones distintas, que pueden llegar a complementarse o solaparse, a saber: a) cuando los modelos o paradigmas establecidos no pueden explicar los datos que se manejan y éstos conducen a diversas soluciones para un mismo problema; $b$ ) cuando la metodología al uso no permite la falsación de algunas interpretaciones. A veces, las rupturas son tan profundas que se produce el cambio o sustitución del antiguo paradigma, mostrándose en estos casos diferencias irreconciliables entre las viejas ideas y las modernas. A esta última clase de rupturas es a lo que habitualmente se denominan revoluciones kuhnianas.

Hay que hacer notar que aunque las controversias son útiles y necesarias para el desarrollo de las hipótesis o teorías, no siempre provocan el avance del conocimiento científico, especialmente cuando los análisis historiográficos correspondientes devienen en errores conceptuales que se integran en las disciplinas y permanecen afianzados durante muchas décadas.

3) Actos epistemológicos: Son los mecanismos por los cuales se van superando los obstáculos epistemológicos. Favorecen, por lo tanto, las rupturas con las conceptualizaciones antiguas, provocando los cambios correspondientes y mejorando la visión científica que se posee de la realidad. Como veremos, dentro de estos mecanismos juega un papel esencial la utilización de la historia de la ciencia, especialmente cuando se intenta una reconstrucción lakatosiana de los procesos que han condicionado al avance del conocimiento científico. 
Así, pues, en este modelo de cambio científico, las rupturas epistemológicas provocan la superación, mediante la contradicción, del modelo preestablecido de adquisición del conocimiento. Sin embargo, para Capel (1980), en muchas ocasiones lo importante en sí no es el cambio producido, sino la permanencia de antiguas concepciones. Éstas pueden subsistir ocultas bajo formas distintas, sobreviviendo a sus orígenes y subyaciendo en muchas teorías posteriores. Bajo esta perspectiva, ¿será, por ejemplo, la hipótesis Gaia una versión «moderna y actualizada» del organicismo griego? En las revoluciones kuhnianas no se daría la continuidad conceptual subrayada por William Whewell en la primera mitad del siglo pasado para el mismo concepto. En esto estriba precisamente una de las diferencias fundamentales entre ambas concepciones.

\section{LOS CONCEPTOS ESTRUCTURANTES}

En relación con las concepciones básicas bachelardianas, Gagliardi $(1983,1986)$ ha desarrollado, dentro del modelo constructivista, la idea de los conceptos estructurantes. Se trata de conceptos que van a transformar el sistema cognitivo del alumno de tal manera que le van a permitir, de una forma coherente, adquirir nuevos conocimientos, por construcción de nuevos significados, o modificar los anteriores, por reconstrucción de significados antiguos. De ahí la importancia de tener en consideración las ideas previas de los alumnos en cuanto a la identificación de los conceptos estructurantes y de sus orígenes. Estamos, pues, ante la catarsis bachelardiana.

Una herramienta imprescindible para el análisis de estos conceptos es la historia de la ciencia. Ésta nos va a ayudar a reconocer cuáles han sido los conceptos estructurantes que condicionaron el progreso científico (Gagliardi, 1986). Es importante, además, identificar sus orígenes, para poder actuar, por un lado, sobre los propios conceptos estructurantes y, por otro, sobre las bases en las que se apoyan. Muchas veces actuamos correctamente sobre un determinado obstáculo epistemológico y, sin embargo, no observamos la ruptura correspondiente, sencillamente porque su base de apoyo original permanece oculta para nosotros y, por lo tanto, intacta. Sólo la utilización adecuada de la historia de la ciencia nos va a permitir una doble actuación, contribuyendo de esta forma a la superación de los obstáculos epistemológicos correspondientes. El uso de la historia de la ciencia nos ayuda, además, en la definición de contenidos así como a su secuenciación (no sólo el qué, sino también el cuándo) para afrontar un proceso de enseñanza-aprendizaje (Gagliardi, 1988; Gagliardi y Giordan, 1986; García Cruz, 1996; Pedrinaci, 1993a, b, c, 1994).

\section{ALGUNOS EJEMPLOS PARA LAS CIENCIAS DE LA TIERRA}

La geología se constituyó como ciencia a comienzos del siglo XIX. Sus orígenes pueden seguirse en la obra ya clásica de Adams (1938) y en estudios más modernos de Laudan (1987, 1990) y Gohau (1990). Su repercusión en España ha sido analizada por Pelayo (1991). Con Lyell (1830-33) se reafirmó el carácter normativamente histórico de la geología, del que había estado excluida en las interpretaciones hechas con anterioridad, incluyéndose en estas últimas también las aportaciones de Hutton (1795). Simultáneamente se dieron dos hechos que facilitaron el desarrollo de la geología y que además contribuyeron a ello. Por un lado, su impulso mediante un nuevo carácter empírico, aunque no siempre menos teórico, basado esencialmente en trabajos de campo y, por otro, su separación drástica de la religión, distinguiéndose definitivamente entre ciencia geológica y teología natural derivada del Génesis bíblico. Esto último desembocó en la liberación de la geología de un período de tiempo altamente restrictivo.

En las ciencias de la Tierra se han dado -y se dancontroversias muy importantes e interesantes, tanto desde un punto de vista científico como didáctico. No sólo las clásicas analizadas por Hallam (1983), como Edad de la Tierra o Deriva Continental, sino también otras más modernas, en las que se observan reminiscencias de algunas anteriores. Estos debates actuales van desde procesos de sedimentación no uniforme que implican los estromatolitos o dolomitas, hasta las causas de la extinción de los mamutes, pasando por la duración de los eventos orogénicos o la extensión de la corteza continental, por citar sólo algunos casos significativos (Müller et al., 1991).

El origen primario de una buena parte de los obstáculos que ha tenido que superar la geología reside en las creencias religiosas, la llamada teología natural. El Libro del Génesis, punto de partida de toda la tradición judeo-cristiana, ha sido por sí solo una fuente casi inagotable de obstáculos. A lo largo de los siglos, numerosas concepciones científicas pretendieron acomodar la realidad natural a las revelaciones divinas, puesto que la historia de la Tierra estaba literalmente relatada en la Biblia. La geología, en concreto, era interpretada formando parte de la evidencia bíblica (Gillispie, 1951; Rossi, 1979). En esta influencia religiosa habría que buscar, según Capel (1985), el motivo del sorprendente retraso en la modernización de la ciencia geológica en comparación, por ejemplo, con la física. Las rupturas más importantes, incluso antes de su modernización, consistieron en vencer fundamentalmente todas estas representaciones mítico-religiosas.

Por otro lado, ha existido -y existe- un obstáculo epistemológico básico, ya señalado anteriormente, y que ha influido en todas las ciencias, pero de un forma especial en el desarrollo de la geología. Se trata del énfasis impuesto a partir del siglo XVII por parte del positivismo en los métodos de observación directa, así como en la importancia dada a los datos cuantitativos y su matematización, frente a los procedimientos hipotético-deductivos. Las dificultades que presentan la mayoría de las ciencias de la Tierra para la experimentación y la observación directa de numerosos fenómenos o procesos geológicos, qué duda cabe, han determinado su 
desarrollo y modernización, actuando paralelamente a otros obstáculos epistemológicos o contribuyendo a su afianzamiento.

Vamos a analizar, en el marco de la epistemología con las correspondientes consideraciones históricas, algunos obstáculos que han determinado el desarrollo de la ciencia geológica. Obviamente, no se podrán considerar todos, y algunos importantes quedarán fuera de esta reflexión.

1) La edad de la Tierra. Las ideas sobre la edad del planeta, y por extensión sobre la noción de tiempo geológico, cuya complejidad didáctica ha sido convenientemente señalada por Pedrinaci (1993b,c), han venido condicionadas, en primer lugar, por el creacionismo. No sólo el principio de la Tierra estaba al «alcance» de las Escrituras; también lo estaba, evidentemente, su fin. A lo largo de muchos siglos, una dimensión temporal sólo de varios milenios obstaculizó el desarrollo y la aceptación de numerosas concepciones que daban una explicación más coherente de la realidad natural. Además, los cambios tanto locales como globales necesarios para poder establecer una mayor antigüedad eran imperceptibles (volveremos sobre este aspecto en el punto 3 ). Así, por ejemplo, Steno, ante una edad de apenas 6.000 años para la Tierra, se vio «abocado» al catastrofismo a pesar de que sus interpretaciones estratigráficas eran gradualistas y actualistas. (Como veremos, éste y otros ejemplos que se citan más adelante pueden interpretarse de una forma totalmente distinta.) La complejidad de esta idea explica que el debate sobre la edad de la Tierra se mantuviera hasta las primeras décadas del siglo XX (Hallam, 1983), viéndose obstaculizado por el prestigio y la influencia de algunos de los intervinientes, concretamente por Lord Kelvin, ejemplo típico de actitud dogmática en el seno de la comunidad científica.

2) La inmutabilidad. Las ideas religiosas conducían al fijismo o inmutabilidad general del planeta, es decir, a la creencia en que la distribución de los grandes caracteres de la Tierra, continentes y océanos especialmente, había quedado establecida desde la creación. La observación directa no era favorable a la existencia de cambios en la superficie terrestre. El diluvio universal había llegado a modificar tan sólo las líneas de costa tras retirarse las aguas. Se da la circunstancia de que algunos autores a lo largo de los siglos XVII y XVIII, como Kirwan, por ejemplo, señalaron gráficamente la permanencia de esta distribución de continentes y cuencas oceánicas tras el diluvio, con una coincidencia total con los litorales representados en la cartografía de la época. La idea de permanencia de los caracteres terrestres obstaculizó sobremanera el desarrollo y la aceptación de algunas concepciones, especialmente aquéllas que implicaban modificaciones o grandes cambios en la superficie terrestre, como, por ejemplo, las teorías movilistas.

El fijismo como base de la inmutabilidad del planeta ha sido, en relación con el creacionismo, quizás uno de los obstáculos que más han tardado en superarse. En estos debates se partió de perspectivas sistemáticas muy distintas y que durante muchos siglos permanecieron estan- cadas en forma de procesos cíclicos y, por lo tanto, con un carácter ahistórico. Uno de estos sistemas fue el catastrofismo. Especialmente por parte de los diluvialistas, influyó en la idea de que todos los caracteres terrestres, los mayores y también los menores, tuvieran un origen. Así nació Neptunismo de Werner, basado casi exclusivamente en la influencia omnímoda e indiscutible prestigio de su autor. Para éste, y para sus discípulos cegados por el dogmatismo werneriano, el origen de todas las rocas, y su disposición en la superficie terrestre, se hallaba en los procesos de separación de materiales tras el diluvio universal. A esta visión se oponían tanto los vulcanistas como los plutonistas (Gohau, 1987; Hallam, 1983), más cercanos a la realidad natural y con más apoyo observacional, del que carecía Werner. Vemos, pues, que considerar diferentes orígenes para los diferentes tipos de rocas no ha sido siempre tan evidente (Pedrinaci, 1993a).

El fijismo también se manifestaría, asociado con el origen de las rocas, en las ideas sobre la naturaleza y el origen de los fósiles. Para Marchal (1980) existen dos postulados epistemológicos básicos dentro del discurso paleontológico actual, a saber: $a$ ) los fósiles son restos, bien de organismos, bien de sus actividades, modificados por procesos físicos, químicos o biológicos; y b) tanto las estructuras como los comportamientos de los seres que vivieron en el pasado pueden conocerse por referencia a los actuales.

Estos conceptos, que ahora nos resultan tan familiares y evidentes, tardaron en establecerse sólidamente varios siglos (Ellenberger, 1988; Gohau, 1966, 1987; Rudwick, 1972). Y, aunque para los clásicos griegos y árabes, en general, los fósiles eran restos de organismos, las ideas religiosas durante la Edad Media sólo los interpretan como tales en tanto que constituían una «evidencia» del diluvio. Además, se daba aquí una aparente contradicción desde el punto de vista metodológico. Por un lado, la aceptación catastrofista del diluvio universal en parte se debía a un análisis actualista de las conchas fósiles. La presencia de estos fósiles marinos en lo alto de las montañas era una prueba de la existencia del diluvio, por una simple referencia a los moluscos actuales como organismos marinos: sólo como tales podían haber llegado hasta allí. Más recientemente, se daba también una contradicción tal entre las concepciones biológicas y geológicas, que Lyell, por ejemplo, renunció a aplicar su visión actualista-uniformitarista al campo de la biología (Laudan, 1982), puesto que numerosos fósiles, especialmente de vertebrados, no tenían parangón alguno dentro de la fauna conocida en aquella época. Es obvio que tampoco lo tienen en ésta, pero el proceso evolutivo y la actual aproximación neocatastrofista a las extinciones biológicas permiten una explicación bastante coherente (Hsü, 1986; Agustí, 1996).

Vemos, pues, que el actualismo-uniformitarismo -y ésta no fue la única ocasión (volveremos sobre él en el punto 5)- se configuró como un auténtico obstáculo epistemológico para el desarrollo, en este caso, de algunos aspectos de la paleontología. No olvidemos que el más insigne representante y gran impulsor de esta última en 
el siglo XIX, Georges Cuvier, no sólo ha sido considerado como uno de los «padres naturales» del catastrofismo, sino que, además, su labor paleontológica, por otro lado ingente y transcendental, estuvo siempre destinada a demostrar «su» sistema (Cuvier, 1812, 1825), aunque no le eran en absoluto ajenas las visiones actualistas.

3) El organicismo. De origen primitivo, la visión del mundo como un organismo tuvo una enorme influencia desde la antigüedad clásica griega en múltiples ideas sobre el funcionamiento de la Tierra en analogía con los procesos vitales. Una de ellas, como ejemplo por su transcendencia en cuanto a su persistencia en el tiempo, fue la idea del fuego interior, en la que se basó Kircher para su mundo subterráneo. El sentido común y los mecanismos intuitivos en los que se sustentaba, desembocó en la imagen de un planeta en lento proceso de enfriamiento (Ellenberger, 1988). Así nace la teoría de la contracción, que ya se deja entrever primariamente en los Principia cartesianos, y que dominó durante más de tres siglos cualquier visión posible sobre el origen de las montañas, incluyendo las aportaciones de Élie de Beaumont o Dana (Gohau, 1983). Sólo con la emergencia ya entrado el siglo XX de la tectónica de placas, se abordó el problema dentro del marco del funcionamiento global del planeta. Sin embargo, cuando se analiza la orogénesis dentro del desarrollo histórico de este marco, comprendemos las dificultades que tuvo que vencer, tanto conceptuales como metodológicas. Todavía aquí perdura la controversia en relación, por ejemplo, con el tiempo de duración de los procesos orogénicos, tanto en lo referente a la construcción como a la destrucción de montañas -en ambos casos, incluso, sobre los mecanismos-, o con el origen de algunos mantos de corrimiento como los del Glarus, entre otros aspectos.

4) El movilismo geológico. Frente a una parte de las ideas fijistas, el movilismo geológico se ha configurado como un concepto estructurante de gran importancia dentro de las más modernas ciencias de la Tierra. Sin embargo, dentro de las teorías movilistas, hay que distinguir dos tipos fundamentales, cuya consideración ha sido muy distinta por parte de los geólogos.

Por un lado, estaban aquellas ideas que implicaban movimientos en la vertical definidos por el principio de la isostasia. De acuerdo con éste, las masas continentales de sial descansaban en equilibrio isostático sobre las del sima, más denso y profundo, condicionando los ascensos y descensos de la corteza terrestre. La aceptación del principio de la isostasia se vio favorecida al ser incorporada a finales del siglo XIX por Dana y Suess a sus modelos generales del planeta. Así, la teoría de la contracción ya mencionada y el ajuste isostático explicaban perfectamente tanto el origen de los continentes y cuencas oceánicas como la distribución de las cordilleras, llanuras y plataformas continentales. Las fuerzas compresivas laterales necesarias se habían producido al «acomodarse» la corteza al colapso debido a la contracción por enfriamiento. De acuerdo con esta filosofía geológica global, no había ninguna duda de que los grandes caracteres terrestres habían quedado configurados como tales ya desde el precámbrico. Frente a esta situación, apareció a principios del siglo XX la teoría de la deriva continental de Wegener En ella se proponían fundamentalmente dos ideas revolucionarias: por un lado, los continentes habían estado unidos en el pasado geológico formando «una sola tierra» y, por otro, a partir del cretácico, las masas continentales se fracturaron y se desplazaron en la horizontal, siendo el origen y la actual distribución de tierras, mares y cordilleras una consecuencia directa de estos desplazamientos.

En el desarrollo de esta teoría movilista estuvieron implicados, por un lado, una serie de conceptos estructurantes que ya hemos considerado con anterioridad y que están íntimamente relacionados entre sí: sin poner en duda las creencias bíblicas, y, dentro de ese escepticismo fundamental, sin una dimensión temporal lo suficientemente amplia, iba a ser prácticamente imposible asimilar no sólo el carácter cambiante del planeta, sino también las características de esa mutabilidad para llegar a explicar fenómenos tales como el origen de las cordilleras o la distribución y el origen de los océanos y de los continentes. Hay que tener en cuenta que a principios del siglo XX, la Tierra «aún no tenía edad suficiente» donde enmarcar temporalmente las ideas de Wegener, y éste además carecía de las «fuerzas suficientes» para mover sus continentes, así como de unas causas que no se opusieran a la filosofía geológica «oficial», en especial de Dana y Suess.

Por otro lado, existió un obstáculo epistemológico difícilmente superable y sobre el que volvemos a insistir: la metodología inductiva positivista de los detractores de Wegener, al que se oponía el método hipotético-deductivo del meteorólogo alemán, hecho éste que se vio reflejado en la mayoría de las críticas contra la deriva continental.

5) El actualismo-uniformitarismo. Vamos a analizar, por último, un concepto que, poco a poco, sin darnos cuenta, se ha ido convirtiendo en un importante obstáculo epistemológico. En los ámbitos científicos (y también en los didácticos, aunque en este caso generalmente de forma anecdótica) está asentada una vieja idea que ha llegado a convertirse en verdad absoluta y, por lo tanto, en un dogma más. Se trata del tan controvertido debate entre el catastrofismo y el actualismo-uniformitarismo. Además, se suelen utilizar estos dos últimos términos como sinónimos. Aunque en su origen sí lo fueron, hoy día, de acuerdo con Rudwick (1976), representan significados distintos: el uniformitarismo (igual que el catastrofismo) es un sistema o teoría, mientras que el actualismo es una metodología y, por lo tanto, compatible con ambos sistemas.

Algunos estudios sobre historia de la geología, destacando el análisis de Gould (1987), muestran que el mencionado debate es una verdad sólo a medias. Dicha controversia, en realidad, nunca tuvo lugar en sus orígenes, por una razón relativamente simple: no todos los catastrofistas partían de los mismos presupuestos ideológicos. Las ideas tanto de catástrofes naturales como de uniformidad aparecen ya en los filósofos griegos en relación con las renovaciones planetarias. Sólo cuando la explicación 
causal se intenta integrar en el dogmatismo religioso, lo que fue alentado por Buckland, surge el debate. Así, el auténtico enfrentamiento se produjo entre los catastrofistas «bíblicos», en especial los diluvialistas, y los uniformitaristas, en su intento de deshacerse, al igual que algunos catastrosfistas no bíblicos como Cuvier, definitivamente de las influencias religiosas.

Éste es el motivo de que en Steno o Cuvier, o en la interpretación de los fósiles citados con anterioridad, cohabitasen concepciones catastrofistas con métodos actualistas, puesto que no eran tan incompatibles o excluyentes. Incluso el propio Lyell lo hizo también, introduciendo hábilmente en las sucesivas ediciones de sus Principles diferentes conceptos de uniformidad, sin negar algunos aspectos catastrofistas que compartía con Cuvier. Así llegó a crear, intencionadamente quizás como apunta Gould (1987), una cierta confusión en los científicos de su época, y también en los actuales.

Sin embargo, tras salir «victorioso» de este debate (Canon, 1960), a pesar de algunas llamadas de atención y críticas al respecto (Gould, 1965, 1970, 1982, 1984; Gould y Eldredge, 1977; Krinine, 1956; entre otros), el actualismo-uniformitarismo se ha ido configurando como un obstáculo epistemológico transcendental en las ciencias de las Tierra, y en cierto sentido también para las ciencias del espacio y de la vida.

La objeción principal que se le puede hacer, de acuerdo con Feuillée (1976), no se dirige contra su espíritu metodológico porque sea incorrecto, sino porque ha sido utilizado de una manera irreflexiva y sistemática durante más de cien años, negando cualquier otra posibilidad que no sea gradualismo y uniformidad. De esta forma se ha llegado a confundir, como bien señala Hsü (1986), los fenómenos improbables -considerando la extensión del tiempo geológico- con los imposibles. Veamos algunos ejemplos concretos muy significativos.

Actualmente es muy difícil negar la evidencia de eventos catastróficos que han afectado tanto a la Tierra como a otros planetas del sistema solar (Ager, 1971, 1993; Albritton, 1989; Anguita, 1992; Berggren y Couvering, 1984; Meisel et al., 1994; Morrison y Chapman, 1990; entre otros muchos). La caída de meteoritos que provocaron cambios climáticos y extinciones masivas en la biosfera, la existencia de grandes inundaciones locales, la desertificación de cuencas marinas o incluso un proceso evolutivo que, en buena parte, nada tiene que ver ni con el gradualismo ni con la uniformidad... han dejado sus huellas sobre la Tierra; un rastro que, sin embargo, la ciencia más ortodoxa se ha negado a ver hasta hace pocos años, y sólo en algunos casos. Otro ejemplo muy conocido: un análisis actualista de los dinosaurios, que los ha «convertido» en reptiles $\mathrm{y}$, por lo tanto, en «animales de sangre fría». Sin embargo, existen evidencias suficientes de que se trataba de animales homeotermos que, por otro lado, tenían que ver más con las aves actuales que con los reptiles.

¿Estamos ante nuevas evidencias «fragmentarias» que se oponen a «datos sólidos», como ya ocurriera en otras ocasiones (Skinner, 1986), contradiciendo ahora al uniformitarismo como sistema dogmático, o bien se trata de un retorno a la «geopoesía»? El debate está servido desde hace años.

\section{OBSTÁCULOS EN EL ÁMBITO ESCOLAR}

Sin entrar en detalles específicos de cada área del currículo, vamos a considerar diversos obstáculos que pensamos que dificultan el aprendizaje escolar en general de las ciencias de la Tierra y que pueden derivarse directamente de un análisis histórico del desarrollo de las mismas:

- La imposibilidad de observación directa asociada a la dificultad de experimentación planea como un importante obstáculo en muchos fenómenos y procesos geológicos en tanto que al alumnado le resulta muy difícil asumir, por ejemplo, el tiempo geológico, la orogénesis o los desplazamientos continentales, sencillamente por la imposibilidad real de verlos o manipularlos.

- La inmutabilidad es lo que habitualmente se observa, a excepción de situaciones muy puntuales, como los terremotos o las erupciones volcánicas. Este fijismo está en íntima relación con otro concepto estructurante de gran relevancia, cual es la idea de las rocas como archivos o documentos, y su comprensión, por extensión, facilita la del concepto de tiempo geológico. En relación con el fijismo, de acuerdo con Pedrinaci (1993a), el creacionismo derivado de las creencias religiosas actualmente no representa un obstáculo en la enseñanzaaprendizaje de la geología.

- Es difícil que el alumnado asimile la idea de globalidad, es decir, la integración de cualquier fenómeno o proceso geológico en el funcionamiento global del planeta, en el sentido, por ejemplo, de que los terremotos o el metamorfismo no son independientes de la orogénesis, del magmatismo o de los desplazamientos corticales, sin tener que recurrir a interpretaciones vitalistas $u$ organicistas.

- A lo largo de todas las ciencias de la Tierra se han hecho -y se hacen- interpretaciones actualistas-uniformitaristas y, sin embargo, se obvia su significado. Es necesario que éste sea conocido por el alumnado, y además también sería útil y conveniente analizar sus orígenes históricos. De esta forma, se pondría en evidencia la peligrosidad de interpretar abusivamente determinados fenómenos geológicos, bien bajo esta perspectiva $o$, desde un punto de vista catastrofista, excluyendo totalmente la otra. Esto ayudaría al mismo tiempo a asimilar la diferencia entre hecho imposible (p.e., los ríos nacen en el mar y desembocan en lo alto de las montañas, no sólo porque observamos lo contrario sino porque lo contradice la ley de la gravedad) y hecho improbable (p.e., la colisión catastrófica de un asteroide o cometa con la Tierra).

- Ante una enseñanza científica generalmente basada en hechos acabados, el alumnado no llega a poseer la 
noción de debate o controversia. Es habitual, pues, que considere la construcción del conocimiento científico como meramente acumulativa En consecuencia, ante diferentes explicaciones sobre un fenómeno, considera la teoría más reciente como la correcta. Las reconstrucciones históricas le permitirán comprender el carácter cambiante de la ciencia, insistiendo también, por otro lado, en que no todo el conocimiento científico es provisional.

- Buena parte de estas dificultades, y concretamente en lo referente a la imposibilidad de reproducir algunas características físicas (tiempos excesivamente largos, grandes profundidades, presiones y temperaturas muy altas, etc.), se pueden superar mediante la modelización o simulación como instrumento de enseñanza-aprendizaje (Elder, 1976). Sin embargo, debe quedar claro desde un principio para el alumnado que un modelo no es la realidad sino una mera representación de la misma, de la que se manejan, por otro lado, un número reducido de variables. En caso contrario podría actuar como obstáculo epistemológico cayendo dentro de la metodología de la superficialidad (Gil y Carracosa, 1985).

Para terminar esta reflexión podemos extraer una conclusión general: profundizando en los obstáculos mencionados dentro de cada apartado del currículo de las ciencias de la Tierra en su contex to histórico, llegaremos a determinar en el marco de la epistemología los condicionantes del avance científico. Al mismo tiempo, el análisis de las ideas previas del alumnado nos facilitarán la comprensión de sus propias dificultades en forma de conceptos estructurantes, que en cierta medida se corresponden con obstáculos epistemológicos o se derivan directamente de ellos.

\section{REFERENCIAS BIBLIOGRÁFICAS}

ADAMS,F.D.(1938). The birth and development of the geological sciences. Nueva York: Dover (ed. 1990).

AGER, D.V. (1971). The nature of the stratigraphical record. Sussex: Wiley (3a. ed., 1993).

AGER, D.V. (1993). The New Catastrophism. Cambridge: University Press.

AGUSTÍ, J. (ed.) (1996). La lógica de las extinciones. Barcelona: Tusquets.

ALBRITTON, C.C., Jr. (1989). Catastrophic episodes in Earth History. Londres: Chapman-Halls.

ANGUITA, F. (coord.) (1993). Catástrofes en la historia del sistema solar: un debate abierto. Cursos de verano de la Universidad Complutense, Madrid, 2-6 de agosto.

BACHELARD, G. (1938). La formación del espíritu científico. México: Siglo XXI. Trad. cast., 1948, 14a. ed., 1987.

BERGGREN, W.A. y COUVERING, J.A. van (eds.) (1984). Catastrophes and Earth History. The New Uniformitarianism. Princeton: University Press.

CANON, W.F. (1960). The uniformitarian-catastrophist debate. Isis, Vol. 51, pp. 38-55.

CAPEL, H. (1980). Organicismo, fuego interior y terremotos en la ciencia española del siglo XVIII. GeoCrítica, núm. 27-28.

CAPEL, H. (1985). La física sagrada. Barcelona: El Serbal.

CUVIER, G. (1812). Recherches sur les ossements fossiles de quadrupèdes. Discours préliminaire. París: Flammarion (ed. 1992).
CUVIER, G. (1825). Discours sur les révolutions de la surface du globe. París: Bourgois (ed. 1985).

ELDER, J. (1976). Las entrañas de la Tierra. Barcelona: A. Bosch. Trad. cast. 1978.

ELLENBERGER, F. (1988). Historia de la Geología. Vol. 1. De la antigüedad al siglo XVII. Barcelona: Labor-MEC. Trad. cast., 1989.

FEUILLÉE, P. (1976). Le problème de l'actualisme en géologie. Revue des Questions Scientifiques, Vol. 147(2), pp. 195-208.

GAGLIARDI, R. (1983). Les concepts structurants en biologie. Actes des Journées Internationales surl'Education Scientifique, París, Vol. 7, pp. 471-476.

GAGLIARDI, R. (1986). Los conceptos estructurales en el aprendizaje por investigación. Enseñanza de las Ciencias, Vol. 4(1), pp. 30-35.

GAGLIARDI, R. (1988). Cómo utilizar la historia de las ciencias en la enseñanza de las ciencias. Enseñanza de las Ciencias, Vol. 6(3), pp. 291-295.

GAGLIARDI, R. y GIORDAN, A. (1986). La historia de las ciencias: una herramienta para la enseñanza. Enseñanza de las Ciencias, Vol. 4(2), pp. 253-258.

GARCÍA CRUZ, C.M. (1996). La historia de la ciencia como hilo conductor de una unidad didáctica: tectónica de placas. Enseñanza de las Ciencias de la Tierra, Vol. 4(1), pp.59-66.

GIL, D. y CARRASCOSA, J. (1985). Science learning as a conceptual and methological change. European Journal of Science Education, Vol. 7, pp. 231-236. 
GILLISPIE, C.C. (1951). Genesis and geology. Cambridge: Harvard University Press (ed. 1996).

GOHAU, G. (1966). Les fossiles, naissance et formation d'une idée scientifique. Textes et Documents, Cahiers Pédagogiques, IPN, París.

GOHAU, G. (1983). Idées anciennes sur la formation des montagnes. Cahiers d'Histoire et de Philosophie des Sciences, 7. CNRS.

GOHAU, G. (1987). Histoire de la géologie. París: La Découverte.

GOHAU, G. (1990). Les sciences de la terre aux XVIIe et XVIIIe siècles: Naissance de la gélogie. París: A. Michel.

GOULD, S.J. (1987). La flecha del tiempo. Madrid: Alianza. Trad. cast., 1992.

GOULD, S.J. (1965). Is uniformitarianism necessary? American Journal of Science, Vol. 263, pp. 223-228.

GOULD, S.J. (1970). Private thoughts of Lyell on progression and evolution. Science, Vol. 169, pp. 663-664.

GOULD, S.J. (1982). Punctuated equilibrium -a different way of seeing. New Scientist, Vol. 94(1301), pp. 137-141.

GOULD, S.J. (1984). Towards the vindication of punctuational change, en Berggren y Couvering (1984), cap. 1, pp. 9-34.

GOULD, S.J. y ELDREDGE, N. (1977). Punctuated equilibria: the tempo and mode of evolution reconsidered. Paleobiology, Vol. 3(2), pp. 115-151.

HALLAM, A. (1983). Grandes controversias geológicas. Barcelona: Labor. Trad. cast. 1985.

HSÜ, K.J. (1986). La gran extinción. Barcelona: A. Bosch. Trad. cast., 1989.

HUTTON, J. (1795). Theory of the Earth. Edimburgo: CadellDavies \& Creech.

KRYNINE, P.D. (1956). Uniformitarianism is a dangerous doctrine. Journal of Palaeontology, Vol. 30, pp. 1003-1004.

LAUDAN, R. (1982). The role of methodology in Lyell's science. Studies in History and Philosophy of Sciences, Vol. 13(3), pp. 215-249.

LAUDAN, R. (1987). From Mineralogy to Geology. The Foundations of a Science, 1650-1830. Chicago: University Press.
LAUDAN, R. (1990). The history of geology, 1780-1840, en Olby, R.C., Cantor, G.N., Christie, J.R.R. y Hodge, M.J.S. (eds., 1990). Companion to the History of Modern Science. Londres: Rouletge, cap. 20, pp. 314-325.

LYELL, C. (1830-1833). Principles of Geology. Chicago: University Press. Tomos I, II y III (facsímil 1990 de la 1a. ed. inglesa).

MARCHAL, P. (1980). La paléontologie ou de l'interprétation scientifique des fossiles. Défrichage épistémologique. Revue des Questions Scientifiques, Vol. 151(1), pp. 33-56.

MEISEL, D.D., DESURDIS, R.I., Jr., AMENGUAL, C., DE TORRES, C., LÓPEZ, C., y BERNABEU, M. (1994). Catástrofes cósmicas. Barcelona: Infortécnica.

MORRISON, D. y CHAPMAN, C.R. (1990). The new catastrophism. The Skeptical Inquirer, Vol. 14, pp. 141-152.

MÜLLER, D.W., McKENZIE, J.A. y WEISSERT, H. (eds., 1991). Controversies in modern geology. Londres: Academic Press.

PEDRINACI, E. (1992). La rocas tienen una historia que contarnos. Aula de innovación educativa, Vol. 4-5, pp. 33-35.

PEDRINACI, E. (1993a). Concepciones acerca del origen de las rocas: una perspectiva histórica. Investigación en la Escuela, Vol. 19, pp. 89-103.

PEDRINACI,E. (1993b). La construcción histórica del concepto de tiempo geológico. Enseñanza de las Ciencias, Vol. 11(3), pp. 315-323.

PEDRINACI, E. (1993c). Utilidad didáctica de la historia de la geología. Educación abierta, 105, pp. 111-145.

PEDRINACI, E. (1994). La historia de la geología como herramienta didáctica. Enseñanza de las Ciencias de la Tierra, Vol. 2(2-3), pp. 332-339.

PELAYO, F. (1991). Las teorías geológicas y paleontológicas durante el siglo XIX. Madrid: Akal.

ROSSI, P. (1979). The dark abyss of time. Chicago: University Press. Trad. ingl., 1984, ed. 1987.

RUDWICK, M.J.S. (1972). The meaning of fossils. Chicago: University Press (2a. ed., 1985).

SKINNER, B.J. (1986). Can you really believe the evidence? Two stories from geology. American Scientist, Vol. 74(4), pp. 400-409.

[Artículo recibido en septiembre de 1996 y aceptado en septiembre de 1997.] 